\title{
Digestibility and balance in ruminants
}

\section{By F. W. Wainman, Rowett Research Institute, Greenburn Road, Bucksburn, Aberdeen $A B 2{ }_{9} S B$}

Farm ruminants are large animals and their size creates problems for the experimenter. They are expensive because they are slow to mature, require a lot of food and they have an alternative use as human food. Thus experiments which involve the slaughter of numbers of domestic ruminants and the destructive analysis of their carcasses become almost prohibitively costly, and this is the reason why balance trials are often preferred, for if these are properly carried out the animals remain alive at the end of the experiment.

Large size of necessity means expensive housing and may imply a more careful experimental approach, in that replication on a large scale or indeed repeating an experiment can be very costly. There are other difficulties associated with handling large animals and a certain amount of physical strength is required of the investigator. The excreta, particularly that of cattle is bulky, semi-liquid and difficult to deal with, compared with that of the rat or rabbit.

The slow rate of growth means that experimental treatments particularly dietary ones may take months or even years to register their effect on the animals and thus progress may be comparatively slow. It is because of these experimental difficulties that the nutritional requirements of the dairy cow are less fully documented than those of the rat.

In addition to its large size the ruminant has a complex gut, it has evolved to deal with an herbivorous diet containing large amounts of cellulose. This complexity is a major factor to be considered in both of the digestibility methods, namely the direct and indirect.

\section{Direct approach}

\section{Digestibility}

The direct approach to digestibility involves collecting the faeces which correspond to a particular intake of feed and measuring the disappearance of the chosen component. With simple-stomached animals two markers may be fed which pass through the gut and identify the faeces resulting from food ingested between the feeding of the markers. In the ruminant, individual meals do not pass through the gut in an orderly fashion like tube trains through a tunnel, but a considerable amount of mixing takes place in the reticulo-rumen and feed particles pass on only when they have been sufficiently comminuted by the processes of rumination and digestion. Thus the complete elimination of the residue of a fibrous meal may take as long as $10 \mathrm{~d}$, the length of time depending both upon the nature of the feed and the feeding level (Blaxter, Graham \& Wainman, 1956). This 
relatively slow rate of passage makes it essential that each digestion experiment is preceded by a preliminary period during which the experimental feed is given in the same amounts at each meal so that anything remaining from the previous feed is eliminated, and relatively uniform rate of passage is established. The work of Blaxter et al. (1956) showed that the necessary length of this period varied with type and level of feed, but it is usual for it to extend over 7-1 $4 \mathrm{~d}$ and ro $\mathrm{d}$ may be used in almost all cases. The work of Blaxter and his colleagues also showed that one of the major sources of error attached to the measurement of digestibility was the so called 'end period error'. This arises because however regular the feeding pattern the faecal excretion is irregular, and, if the collection period is short, the inclusion or exclusion of the product of one particular defaecation can seriously affect the accuracy of the digestibility measurement. However, the magnitude of the error is inversely proportional to the number of days over which the faecal collection is made.

With simple-stomached animals such as the pig the beginning and end of the collection period may be signalled by the arrival of stained particles in the faeces or by the addition of coloured polystyrene granules or other marker to the food. With pig experiments the usual preliminary period is of the order of $6 \mathrm{~d}$ and collections may be made over 5 to $\mathrm{II} \mathrm{d}$. It is extremely difficult to harness a pig for the use of faeces bags, urine funnels, etc., so that it is just as well that markers can be used.

\section{Indirect approach, ratio technique, or indicator method}

Over the years there has been interest in methods of determining digestibility which do not involve the time and expense of the total collection method. These methods involve only the sampling and analysing of the feed and excreta, and depend upon the presence in the feed of an indigestible substance which is termed the indicator or reference substance.

Indicators may be either added to the feed or they may be naturally occurring compounds which are regarded as indigestible. The most commonly used additive is chromic oxide, and of the naturally occurring substances lignin, chromogens, silica, crude fibre and faecal nitrogen have all been used. The digestibility of a particular dietary component is then determined by measuring the ratio of that component to the indicator in both feed and faeces.

The method might be thought to have obvious advantages in the grazing situation where the harnessing of animals is a precarious exercise, however there are additional difficulties in that the composition of the feed must be constant if reliable digestibility figures are to be obtained and such constancy is not attainable with grazing animals. Likewise the amount eaten per day is important particularly if external indicators are used, and grazing animals choose their own daily intake.

Care must be exercised when selecting a marker to add to the feed, if reliable results are to be obtained. The marker must move through the gut in a similar manner to the nutrient being studied; some markers tend to be associated with the solid phase of the digesta whilst others may move with the liquid phase. These problems become particularly important when the disappearance of nutrients in a 
particular region of the gut is being studied and it may be necessary to use two markers so that correction can be made for sampling errors (Hogan \& Weston, 1967).

The use of chromic oxide as a marker has recently been studied by Faichney (1972) in his paper 'An assessment of chromic oxide as an indigestible marker for digestion studies in sheep'. In this study recovery of chromic oxide from the faeces of sheep fed continuously on pelleted diets containing the marker ranged between 91 and $101 \%$ and predicted dry matter digestibilities were similar to those obtained by total collection.

The two natural markers occurring in the feed which are most often used are lignin and chromogens. Lignin is not well defined chemically and, although supposedly indigestible, when determined by some methods it does disappear to some extent during its passage through the ruminant gut. Davidson (1954) compared the chromogen method with total collection of the faeces of sheep fed dried grass, and concluded that the chromogen method should be applied extensively only after comparative trials have shown that results for digestibilities agree with those found by reliable collection methods. He found losses of up to $87 \%$ of chlorophylls in the digestive tract and these losses varied greatly from sheep to sheep.

It must be concluded that there are serious drawbacks to the indicator methods but they may be the only possible methods for use when the total collection of faeces is impracticable.

\section{Balance experiments}

Balance experiments have the advantage over slaughter experiments in that they are non-destructive, but, when used with large animals over long periods of time, small errors in estimation may lead to large cumulative errors, and this may result in serious discrepancies between balance and slaughter trials.

When carrying out balance trials all the possible avenues of loss of the nutrient being studied must be taken into account. Thus in man sodium may be lost in tears and sweat as well as in the urine and faeces, whilst in sheep potassium is lost through the skin in suint.

The techniques of, and errors attached to balance trials have been reviewed by Dr Duncan, of the Commonwealth Bureau of Animal Nutrition (Duncan, 1958, 1966, 1967). Dr Duncan deals very fully with the advantages and disadvantages of such trials when used with substances having no gaseous loss. Nitrogen balances and the sources of inaccuracies associated with them are discussed by Martin (1966) and Owen (1967).

At the 1966 Symposium in Glasgow Blaxter (1967) discussed 'Techniques in energy metabolism studies and their limitations'. He gave a full explanation of the methods of determining energy balance both by the respiratory quotient and the carbon nitrogen balance and discussed the errors associated with each.

In the equation Food energy - energy of (faeces + urine + methane + heat) $=$ energy retained, the energy content of the italic terms can be determined with a 
good standard of accuracy in a bomb calorimeter, the major errors arising from sampling techniques and sample preparation.

The determination of energy lost from the animal as methane and heat, demands a more complex procedure. The heat loss can be measured directly and this must equal heat production over a reasonable period of time, taking into account any change in body temperature. Direct calorimeters which measure heat loss from animals (Pullar, 1958) are costly to construct although relatively inexpensive to operate, they really prove their worth in physiological experiments where short term changes in heat loss are of interest.

Heat production of animals may be measured indirectly in two ways either from the carbon and nitrogen balances or by the respiratory quotient (RQ) method. In the $\mathrm{C}$ and $\mathrm{N}$ balance method the content of these elements in all the body losses i.e. faeces, urine, methane, carbon dioxide, hair and skin debris, are deducted from the $\mathrm{C}$ and $\mathrm{N}$ in the food. It is then assumed that energy is retained in the body only as protein or fat and that these have mean nitrogen and carbon contents and energy values.

The RQ method is an energy balance method in which the energy intake and losses are measured but the heat production is calculated from the oxygen consumption and carbon dioxide production.

Thus both the $\mathrm{C}$ and $\mathrm{N}$ balance and $\mathrm{RQ}$ methods require the measurement of methane and carbon dioxide production and the RQ method requires a measurement of oxygen consumption as well. These measurements can be made using either the open-circuit or the closed-circuit principle. In the former the animal is enclosed and the volume of air ventilating the enclosure and the change in its composition is measured (Flatt, Van Soest, Sykes \& Moore, 1958). With the closed-circuit principle the animal is put in an air-tight chamber, the water vapour and carbon dioxide produced are collected in absorbents and weighed. The oxygen consumption is usually measured volumetrically, and methane is allowed to accumulate and is measured by gas analysis using either physical or chemical methods (Wainman \& Blaxter, 1967).

The errors involved in close circuit respiration calorimetry are discussed by Graham, Blaxter \& Armstrong (1958) and by Blaxter (1967).

Estimates of balance are open to the kinds of errors discussed when considering digestibility arising because defaecation, urination and belching are discrete events and not continuous functions. Errors of sampling and of analysis have also to be considered. However, Blaxter ( 1967$)$ concludes: 'it appears that provided great care is taken in the very considerable work involved in balance trials there is no reason to suppose that energy retention measured by these methods is inaccurate or biased in any significant way. Their limitation lies solely in the prodigious amount of work they entail.'

\section{Some factors affecting digestibility measurements}

\section{Species differences in digestibility}

In their recent book Schneider \& Flatt (1975) state categorically that 'data for 
feeds that are intended to be fed to many millions of cattle should be obtained with cattle' and very few would disagree with this as an ideal. Cattle cannot be regarded purely as scaled-up sheep and Schneider \& Flatt write: 'The burden of the proof is still on those who would use sheep instead of cattle to evaluate feeds'. In our work at the Rowett Research Institute we use mostly sheep but have cattle available, but before committing our main effort to work with sheep a literature survey was carried out to identify those sheep-cattle comparisons where exactly the same diets had been given to both species (Wainman, unpublished results). For forages given alone 47 comparisons were found, for concentrates 24 , for mixed rations 64 and for silages alone 19, although it must be remembered that corn silage may react like a mixed diet particularly if cut late. The results of these comparisons are presented graphically in Fig. I. Unfortunately it was not always possible to ascertain from the published results if comparable feeding levels had been used with each species. It can be seen that the greatest differences occur with mixed diets, but these particular diets were mixtures of dried maize grain and hay and it is well known that maize may pass through cattle relatively unchanged. The value for silage which appears to be much better digested by cattle was a different measurement when corn silage was fed with grain.

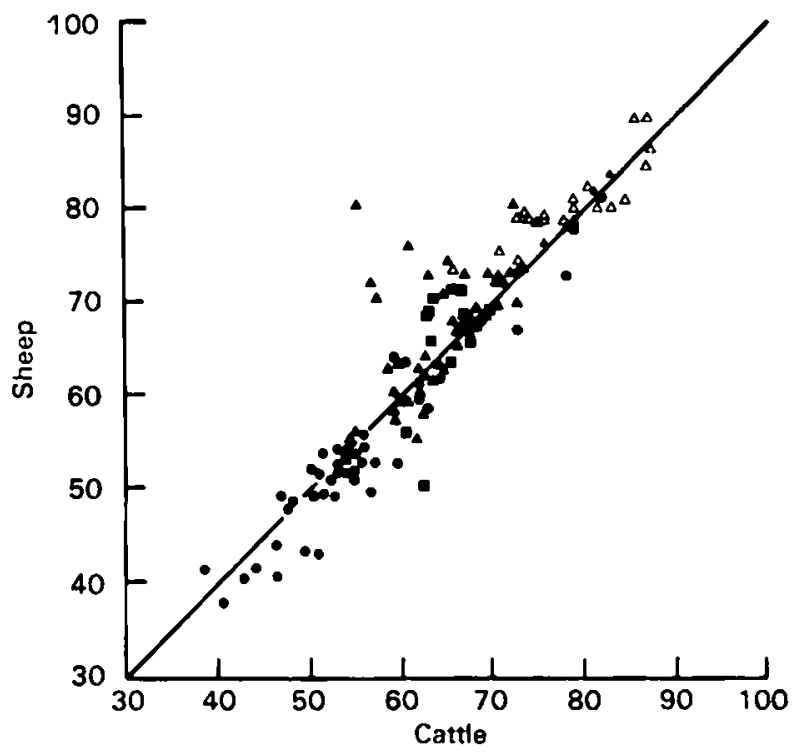

Fig. I. Results of comparisons of feeding levels between sheep and cattle given exactly the same diets. $(\square)$, silages; $(\Theta)$, forages; $(\Delta)$, mixed; $(\Delta)$, concentrates.

With regard to other ruminant species; very low quality forages high in fibre and low in $\mathrm{N}$ as found in the tropics are better digested by goats than by sheep (El Hag, 1976). Red deer have been found to retain food in their digestive tracts for less time than sheep on the same diet, and this is associated with somewhat lower digestibility values especially for cellulose (Kay \& Goodall, 1976). 
In studies at the Hannah Institute no differences in digestive power were found between six breeds of sheep fed dried grass containing $16.4 \%$ crude protein (Blaxter, Clapperton \& Wainman, 1966). Likewise studies with Zebu and European cattle in Africa showed no differences in digestive capacity (French, 1940), neither did similar between-breed studies in Ohio (Klosterman \& Parker, 1976).

In experiments at $\mathrm{Wye}$ College in which wet maize was given with high and low amounts of hay to cows and yearling steers, the latter digested the grain to a greater extent, this was attributed to a longer rumination time, but it may be a size of animal effect and not a sex difference (Wye College, 1974). In fact, I know of no experiments showing a sex difference in digestive powers, although differences in the utilization of metabolizable energy have been reported (Bull, 1970).

\section{Level of feeding effects}

When the amount of food ingested is increased the rate of passage through the gut is also increased, this seems to be the normal process that could be expected with a gut that is not infinitely distensible, and it leads to a fall in digestibility with diets containing forage, although with cattle on high energy barley diets a slight increase may well result (Webster, 1976, private communication). When comparing the digestive capacity of different species or sizes of animal care must be taken that the intakes are related to the metabolic body sizes of the animals, otherwise the digestibility values will be distorted by this plane of nutrition effect.

\section{Associative effects}

This term when applied to digestibility experiments means the influence one food has on the digestibility of another. In many experiments evidence of an associative effect has been shown, but such effects can only be considered together with the term 'balanced ration'. A balanced ration may be defined as one in which all nutrients are present in amounts which do not limit the utilization of other nutrients. However, in the ruminant this concept is complicated by the existence of ruminal digestion. For example there may seem to be enough $\mathbf{N}$ in a ration, but insufficient may become available in the rumen to allow optimum growth of the microbes which digest cellulose, and the same considerations may apply to energy. The time course of the release of nutrients in the rumen must also be considered in this regard, because of the differing rumen retention times for the solid and liquid phases of the digesta.

The recent work of the Feed Evaluation Unit at the Rowett Research Institute failed to show significant associative effects when oats, barleys, and wheat were fed in differing ratios with silages and dried forages (Wainman, Dewey \& McDonald, 1976). Fig. 2 shows the digestibility of energy of wheat, dried grass mixtures of differing proportions and illustrates that there are no obvious associative effects. 


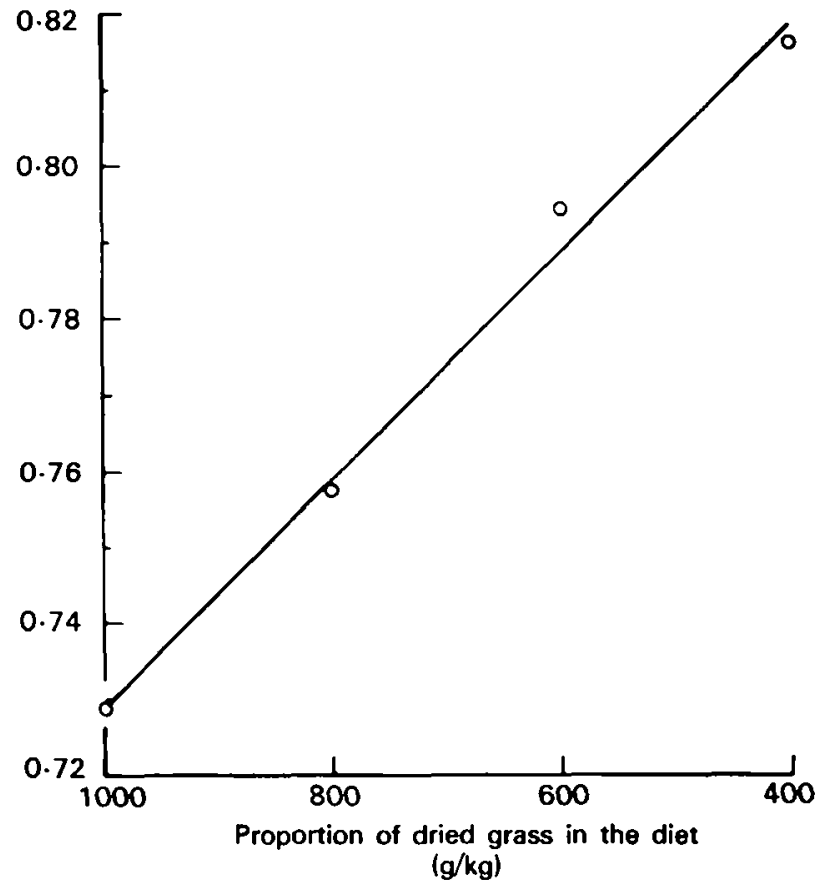

Fig. 2. The digestibility of the energy of rations in which wheat was given in four ratios with dried grass.

In conclusion it may be said that the techniques of digestibility and balance experiments have not changed in the ten years since the last Nutrition Society symposium on the topic, but that centres where such measurements may now be made under standardized conditions have been established in both Scotland and England (rst Report of Feedingstuffs Evaluation Unit, 1975).

\section{REFERENCES}

Barsaul, C. S. \& Talapatra, S. K. (1970). Indian Vet. F. 47, $34^{8}$.

Blaxter, K. L. (1967). Proc. Nutr. Soc. 26, 86.

Blaxter, K. L., Clapperton, J. L. \& Wainman, F. W. (1966). Br. F. Nutr. 20, 283.

Blaxter, K. L., Graham, N. McC. \& Wainman, F. W. (1956). Br. F. Nutr. ro, 69.

Bull, L. S. (1970). Proceedings 1970 University of Maryland Nutrition Conference for Feed Manufacturers, p. 52.

Davidson, J. (1954). F. Sci. Fd Agric. 5, 209.

Duncan, D. L. (1958). Nutr. Abstr. Rev. 28, 695.

Duncan, D. L. (1966). In Recent Adoances in Animal Nutrition [J. T. Abrams, editor] London: Churchill.

Duncan, D. L. (1967). Proc. Nutr. Soc. 26, 102.

El Hag, G. A. (1976). World Rev. Anim. Proc. 12, (3), 43.

Faichney, G. J. (1972). f. agric. Sci., Camb. 79, 493.

Flatt, W. P., Van Soest, P. J., Sykes, J. F. \& Moore, L. A. (1958). Proc. 1st Symp. Energy Metabolism (Copenhagen) p. 53, Statens Husdyrbrugsudvalg Copenhagen (EAAP Publ. no. 8).

French, M. H. (1940). f. agric. Sci. 30, 503.

Goering, H. K. \& Van Soest, P. J. (1970). Forage Fibre Analysis (apparatus, reagents, procedures and some applications) USDA Agriculture Handbook no. 379. 
Graham, N. McC., Blaxter, K. L. \& Armstrong, D. G. (1958). Proc. Ist Symp. Energy Metabolism (Copenhagen) p. 157, Statens Husdyrbrugsudvalg Copenhagen (EAAP Publ. no. 8).

Hogan, J. P. \& Weston, R. H. (1967). Aust. J. agric. Res. 18, 803.

Kay, R. N. B. \& Goodall, E. D. (1976). Proc. Nutr. Soc. 35, 98A.

Klosterman, E. W. \& Parker, C. F. (1976). Res. Bull. 1088, Ohio Ag. Res. \& Dev. Centre.

Martin, A. K. (1966). Br. J. Nutr. 20, 325.

Owen, E. C. (1967). Proc. Nutr. Soc. 26, i 16.

Pullar, J. D. (1958). Proc. Ist Symp. Energy Metabolism (Copenhagen) p. 95, Statens Husdyrbrugsudvalg Copenhagen (EAAP Publ. no. 8).

Rowett Research Institute (1975). Ist Report of the Feedingstuffs Evaluation Unit.

Schneider, B. H. \& Flatt, W. P. (1975). The Evaluation of Feeds through Digestibility Experiments. Athens: Univ. Georgia Press.

Wainman, F. W. \& Blaxter, K. L. (1967). In Energy Metabolism of Farm Animals. [K. L. Blaxter, J. Kielanowski and G. Thorbek, editors]. Newcastle-upon-Tyne: Oriel Press (EAAP Publ. no. 12).

Wainman, F. W. \& Blaxter, K. L. (1972). f. agric. Sci., Camb. 79, 435.

Wainman, F. W., Dewey, P. J. S. \& McDonald, M. S. (1976). In Energy Metabolism of Farm Animals. [M. Vermorel, editor]. Clermont-Ferrand: G. de Bussac. (EAAP Publ. no. Ig).

Wye College Annual Report (1974). p. 43. 